\title{
Substituent Effects on the Sol-Gel Chemistry of Organotrialkoxysilanes
}

Douglas A. Loy*, Brigitta M. Baugher, Colleen R. Baugher, Duane A. Schneider, and

Kamyar Rahimian, Catalysis and Chemical Technologies Department, Sandia National

Laboratories, Albuquerque, NM 87185-1407.

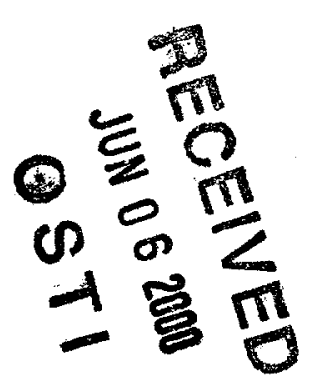

A Manuscript for Chemistry of Materials

Sandia is a multiprogram laboratory operated by Sandia Corporation, a Lockheed Martin Company, for the United States Department of Energy under Contract DE-AC0494AL85000. 


\section{DISCLAIMER}

This report was prepared as an account of work sponsored by an agency of the United States Government. Neither the United States Government nor any agency thereof, nor any of their employees, make any warranty, express or implied, or assumes any legal liability or responsibility for the accuracy, completeness, or usefulness of any information, apparatus, product, or process disclosed, or represents that its use would not infringe privately owned rights. Reference herein to any specific commercial product, process, or service by trade name, trademark, manufacturer, or otherwise does not necessarily constitute or imply its endorsement, recommendation, or favoring by the United States Government or any agency thereof. The views and opinions of authors expressed herein do not necessarily state or reflect those of the United States Government or any agency thereof. 


\section{DISCLAIMER}

\section{Portions of this document may be illegible in electronic image products. Images are produced from the best available original document.}




\section{Introduction}

Silsesquioxanes ${ }^{1}$ have been the subject of intensive study in the past and are becoming important again as a vehicle for introducing organic functionalities into hybrid organic-inorganic materials through sol-gel processing. ${ }^{2}$ Depending on the application, the target hybrid material may be required to be a highly cross-linked, insoluble gel or a soluble polymer that can be cast as a thin film or coating. The former has applications such as catalyst supports and separations media; the latter is an economically important method for surface modification or compatiblization for applying adhesives or introducing fillers.

$$
n \mathrm{R}-\mathrm{Si}\left(\mathrm{OR}^{\prime}\right)_{3}+1.5 \mathrm{n} \mathrm{H}_{2} \mathrm{O} \stackrel{\mathrm{H}+\mathrm{orOH}-}{\longrightarrow}\left[\mathrm{R}-\mathrm{SiO}_{1.5}\right]_{\mathrm{n}}+3 \mathrm{n} \mathrm{R} \mathrm{OH}
$$

Scheme 1. Polymerization of organotrialkoxysilanes to afford crystalline polyhedral oligosilsesquioxanes (upper right) or a range of amorphous polysilsesquioxanes from soluble oligomers to insoluble gels (lower right).

Polysilsesquioxanes are readily prepared through the hydrolysis and condensation of organotrialkoxysilanes, R-Si(OR') $)_{3}$ (Scheme 1), though organotriaminosilane and organotrihalosilane monomers can also be used. The polymers are composed of a monomer repeat unit, $\left(\mathrm{R}-\mathrm{SiO}_{1.5}\right)$, with a single silicon atom attached to other repeat units in the polymer through up to three siloxane bonds. The remaining substituent is an organic group attached to the silicon through a silicon-carbon single bond. Ideally, trifunctional monomers like the organotrialkoxysilanes would be expected to polymerize to highly cross-linked network polymers analogous to silica gels. However, cyclization reactions play an important role in the silsesquioxane polymerization process giving rise 
to soluble crystalline polyhedral oligomers, ${ }^{3}$ amorphous oligomers and polymers

(Scheme 2). There have been numerous reports of gels prepared from methyl-, and vinyl-trialkoxysilanes ${ }^{4-6}$ and a few scattered reports describing gels from hydrido-, ${ }^{7-9}$ chloromethyl-,${ }^{10}$ hexadecyl- and octadecyltrialkoxysilanes. ${ }^{11}$ Still, there has not been a systematic study of the propensity of trialkoxysilanes to form (or not form) gels through the sol-gel process save for one study examining the formation of methyl, ethyl, and vinyl polysilsesquioxane gels. ${ }^{12}$

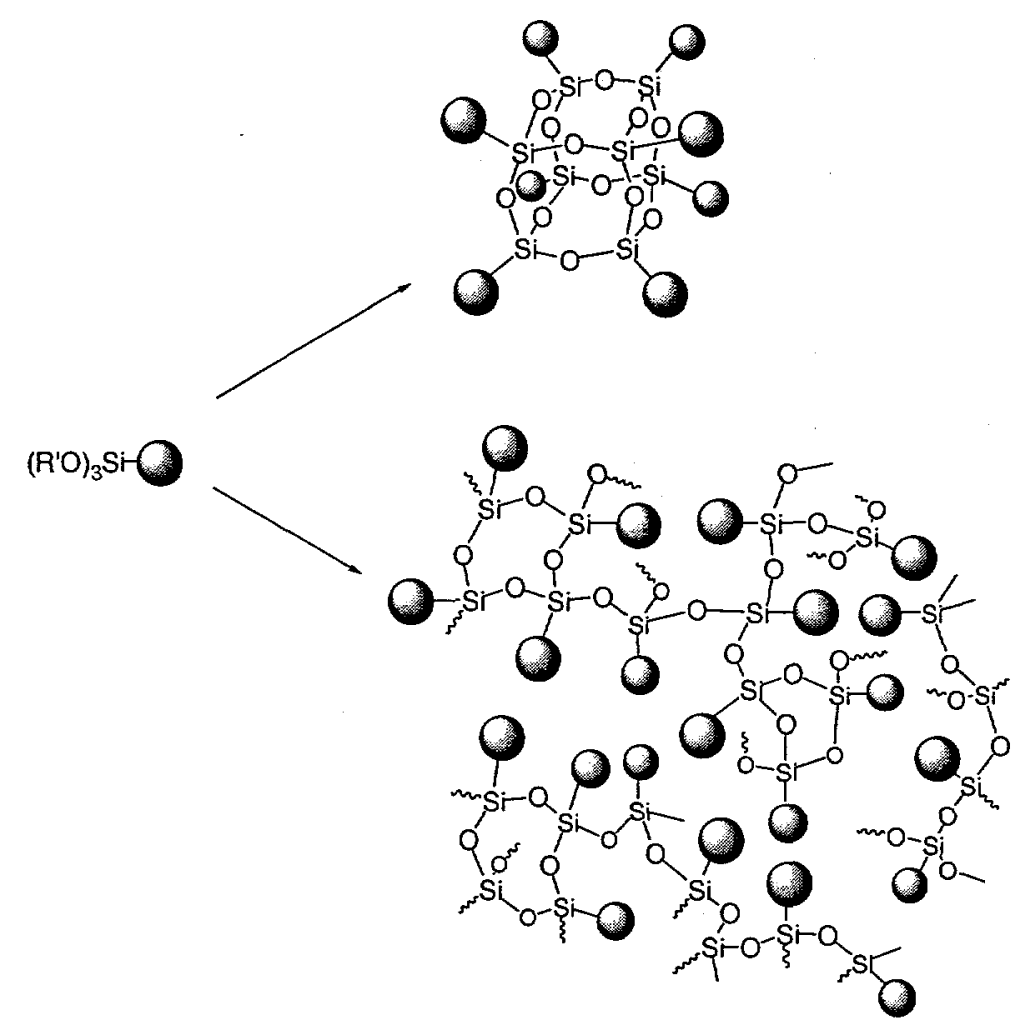

Scheme 2. Hydrolysis and condensation of trialkoxysilanes to give polysilsesquioxanes: $\mathrm{R}=\mathrm{H}$, methyl, ethyl, $n$-propyl, $n$-butyl, $i$-butyl, $t$-butyl, $n$-hexyl, $n$-octyl, $n$-decyl, $n$ dodecyl, $n$-hexadecyl, octadecyl, $n$-octadecyl, cyclohexyl, vinyl, phenyl, benzyl, phenethyl, chloromethyl, (p-chloromethyl)phenyl, tridecafluoro-1,1,2,2-tetrahydrooctyl; $\mathrm{R}^{\prime}=\mathrm{Me}$, Et. 
In this study, we have examined the sol-gel chemistry of a variety of organotrialkoxysilanes with different organic substituents in an attempt to elucidate the requirements for gelation. Most of the organic substituents in this study are hydrocarbons, though a few organofunctional groups, such as chloromethyl- and chloromethylphenyl, were examined as well. The effect of sterics on gelation was examined with the series of saturated, aliphatic substituents: $\mathrm{R}=\mathrm{H}, \mathrm{Me}, i-\mathrm{Pr}$, cyclohexyl, $i-\mathrm{Bu}, t-\mathrm{Bu}$. The effect of the length of a linear alkyl substituent was examined with the series: $\mathrm{R}=\mathrm{H}, \mathrm{Me}, n$-Pr, $n$-Bu, $n$-hexyl, $n$-octyl, $n$-decyl, $n$-dodecyl, $n$-hexadecyl, $n$ octadecyl. Included with this group was a more rigid fluorinated alkyl chain: $\mathrm{R}=$ tridecafluoro-1,1,2,2-tetrahydrooctyl. The effect of olefinic, aromatic, and aromatic functionalized substituents was examined with $\mathrm{R}$ = vinyl, phenyl, benzyl, phenethyl. We also examined substitutents with reactive functionalities that could potentially participate in the sol-gel chemistry: $\mathrm{R}=$ chloromethyl and chlorobenzyl. Because the nature of the alkoxide group has been shown to affect gelation in alkoxysilanes, monomers with methoxide and ethoxide substituents were studied. In all cases, the monomer concentration used in the polymerizations was increased (from $1 \mathrm{M}$ ) until either a gel was obtained, or neat monomer was employed. Aqueous $\mathrm{HCl}$ and $\mathrm{NaOH}$ were used as catalysts in the polymerizations of all of the monomers and anhydrous formic acid was used with a few of the monomers that would not form gels with acid or base. For purposes of comparison, we also prepared silica gels from tetramethoxysilane and tetraethoxysilane under similar conditions.

The polymerization reactions were monitored for formation of gels, insoluble precipitates, soluble polymers, or crystalline polyhedral oligosilsesquioxanes. In earlier 
studies, any insoluble material was often referred to as a gel. In this study, a gel refers to a monolithic gel that forms from the original polysilsesquioxane solution. In order to examine the organic substituents' effects on the material properties, the gels were isolated and characterized by ${ }^{13} \mathrm{C}$ and ${ }^{29} \mathrm{Si}$ CP MAS NMR spectroscopies, electron microscopy, and nitrogen sorption porosimetry.

\section{Experimental}

General Methods. Anhydrous methanol was purchased from Aldrich. Ethanol was distilled from magnesium before use. Triethoxysilane, trimethoxysilane, methyltrimethoxysilane, methyltriethoxysilane, phenyltrimethoxysilane, phenyltriethoxysilane, trimethoxyvinylsilane, triethoxyvinylsilane, $n$ octyldecyltrimethoxysilane, and dodecyltriethoxysilane were purchased from Aldrich. Phenethyltrichlorosilane, cyclohexyltrichlorosilane, t-butyltrichlorosilane, and benzyltriethoxysilane were purchased from Gelest. $i$-Propyltrichlorosilane was prepared from the Grignard reaction between isopropyl magnesium chloride (1.6 $\left.\mathrm{M}^{\text {in }} \mathrm{Et}_{2} \mathrm{O}\right)$ and tetrachlorosilane. Treatment with tetramethylorthoformate and tetraethylorthoformate, afforded $i$-propyltrimethoxysilane and i-propyltriethoxysilane, respectively. $t$ Butyltriethoxysilane and $t$-butyltrimethoxysilane were prepared from $t$ butyltrichlorosilane by esterification with ethylorthoformate or methylorthoformate. Similarly, the cyclohexyl-substituted monomers were prepared from their corresponding trichlorosilane precursor. 2-Phenethyltrimethoxysilane and 2-phenethyltriethoxysilane were also prepared by esterification of phenethyltrichlorosilane. Monomer purities were

checked by GC and ${ }^{1} \mathrm{H},{ }^{13} \mathrm{C}$ and ${ }^{29} \mathrm{Si}$ NMR and distilled if necessary until greater than 
$96 \%$ (GC) was obtained. Because of the importance of using NMR to follow the hydrolysis and condensation of organotrialkoxysilanes, ${ }^{13} \mathrm{C}$ and ${ }^{29} \mathrm{Si} \mathrm{NMR}$ chemical shifts for the monomers used in this study are tabulated in Table 1. ${ }^{29} \mathrm{Si}$ NMR chemical shifts are consistent with those reported for alkyl, vinyl, and aryl substituted trialkoxysilanes.

${ }^{1} \mathrm{H},{ }^{13} \mathrm{C}$ and ${ }^{29} \mathrm{Si}$ solution NMR spectra were recorded on a Bruker DRX $400 \mathrm{MHz}$ spectrometers at a resonant frequency of $400.16 \mathrm{MHz}$, using standard single pulse sequences on a $5 \mathrm{~mm}$ broad band probe. The relaxation delay was 5 seconds, with $8 \mathrm{~K}$ to $32 \mathrm{~K}$ complex points. Experiments were performed at $298 \mathrm{~K}$, using 16-32 scans. Residual solvent peaks or tetramethylsilane were used as internal references for ${ }^{1} \mathrm{H}$ and ${ }^{13} \mathrm{C}$ spectra. ${ }^{29} \mathrm{Si}$ NMR spectra were obtained with neat monomer resulting in a slight (0.2-0.4 pp) downfield shift from those reported in solution experiments. ${ }^{13}$ An external tetramethylsilane $(\delta=0.0)$ sample was used as the reference for ${ }^{29} \mathrm{Si}$ NMR spectra. Infrared spectra were obtained on a Perkin-Elmer 1750 Fourier Transform Infrared spectrophotometer. 
Table 1. ${ }^{13} \mathrm{C}$ and ${ }^{29} \mathrm{Si}$ NMR chemical shifts for organotrimethoxysilanes and organotriethoxysilanes. ${ }^{29} \mathrm{Si}$ NMR's were performed with neat monomer referenced against an external tetramethylsilane standard.

\begin{tabular}{|c|c|c|c|c|}
\hline \multirow[b]{2}{*}{ R-Groups } & \multicolumn{2}{|c|}{ Trimethoxysilyl Monomers } & \multicolumn{2}{|c|}{ Triethoxysilyl Monomers } \\
\hline & ${ }^{13} \mathrm{C}$ (ppm) & $\begin{array}{l}{ }^{29} \mathrm{Si} \\
(\mathrm{ppm})\end{array}$ & ${ }^{13} \mathrm{C}$ (ppm) & $\begin{array}{c}{ }^{29} \mathrm{Si} \\
(\mathrm{ppm})\end{array}$ \\
\hline $\mathrm{H}$ & 49.4 & -55.4 & $57.8,17.6$ & -59.1 \\
\hline $\mathrm{Me}$ & $50.0,-9.2$ & -40.1 & $58.1,18.1,-7.3$ & -44.1 \\
\hline Et & $50.1,5.9,0.8$ & -42.1 & $58.0,18.1,6.3,2.1$ & -45.7 \\
\hline $\mathrm{n}-\mathrm{Pr}$ & $50.1,17.7,16.7,12.6$ & -42.8 & $\begin{array}{c}58.4,18.6,17.9,16.9 \\
13.5 \\
\end{array}$ & -46.4 \\
\hline $\mathrm{i}-\mathrm{Pr}$ & $50.7,16.8,10.3$ & -44.4 & $58.4,18.3,17.0,10.9$ & 47.6 \\
\hline $\mathrm{n}-\mathrm{Bu}$ & $\begin{array}{c}50.2,25.9,24.6,13.4 \\
10.1,8.7 \\
\end{array}$ & -42.6 & $\begin{array}{c}58.2,26.1,24.9,18.2 \\
13.7,10.1\end{array}$ & -46.2 \\
\hline $\mathrm{i}-\mathrm{Bu}$ & $50.1,25.6,23.6,19.3$ & -43.2 & $\begin{array}{c}58.2,25.8,23.8,20.6, \\
18.2\end{array}$ & -46.9 \\
\hline $\mathrm{t}-\mathrm{Bu}$ & $51.0,26.2,17.7$ & -46.4 & $58.8,26.3,18.4,17.5$ & -49.3 \\
\hline $\mathrm{n}-\mathrm{Hex}$ & $50.6,10.2$ & -42.7 & $\begin{array}{l}58.0,32.7,31.4,22.6, \\
22.4,18.0,13.8,10.2\end{array}$ & -45.8 \\
\hline n-Octyl & $\begin{array}{c}50.1,33.1,33.0,29.2 \\
29.1,22.6,13.9,10.4,9.0\end{array}$ & -42.3 & $\begin{array}{c}57.6,32.8,31.6,29.0 \\
22.5,22.3,17.8,13.6 \\
10.1\end{array}$ & -45.8 \\
\hline n-Decyl & $\begin{array}{c}50.0,33.0,31.8,29.5- \\
29.0,22.6,14.2,9.0\end{array}$ & -42.3 & $\begin{array}{c}57.9,33.0,31.8,29.5- \\
29.0,22.6,22.5,18.0 \\
13.8,10.2\end{array}$ & -45.8 \\
\hline Dodecyl & $\begin{array}{c}50.0,33.0,31.8,29.6- \\
29.2,22.5,22.4,13.8,9.0\end{array}$ & -42.3 & $\begin{array}{c}57.9,32.9,31.8,29.5- \\
29.1,22.6,22.5,18.0 \\
13.7,10.2\end{array}$ & -45.7 \\
\hline Hexadecyl & $\begin{array}{l}50.4,33.1,31.9,29.7- \\
29.3,22.63,14.0,9.1\end{array}$ & -42.9 & $\begin{array}{l}58.0,32.7,31.4,22.6 \\
22.4,18.1,13.8,10.2\end{array}$ & -45.8 \\
\hline Octadecyl & $\begin{array}{c}50.1,33.1,31.8,29.1 \\
22.6,13.9,10.5,9.0\end{array}$ & -42.9 & $\begin{array}{c}57.6,32.8,31.6,29.0 \\
28.922 .5,22.3,17.8 \\
\quad 13.6,11.2,10.1 \\
\end{array}$ & -45.7 \\
\hline Cyclohexyl & $50.2,27.3,26.4,22.1$ & -46.3 & $\begin{array}{c}58.3,27.6,26.7,22.8, \\
18.2 \\
\end{array}$ & -49.5 \\
\hline Vinyl & $137.4,129.2,50.6$ & -55.9 & $135.9,129.1,57.8,17.5$ & -59.1 \\
\hline Phenyl & $\begin{array}{c}134.6,130.5,129.3 \\
127.8,50.6\end{array}$ & -55.4 & $\begin{array}{c}134.7,130.9,130.2 \\
127.7,58.6,18.1 \\
\end{array}$ & -58.6 \\
\hline Benzyl & & & $\begin{array}{c}137.5,128.8,128.1 \\
124.5,58.6,20.3,18.1\end{array}$ & -52.2 \\
\hline Phenethyl & $\begin{array}{c}144.2,128.2,127.7 \\
125.6,50.3,28.6,11.2\end{array}$ & -43.7 & $\begin{array}{c}144.4,128.1,127.6 \\
125.4,58.2,28.7,18.1 \\
12.4\end{array}$ & -46.5 \\
\hline $\mathrm{ClCH}_{2}$ & $50.4,22.1$ & -54.8 & $58.7,23.2,17.6$ & -58.7 \\
\hline $\mathrm{ClCH}_{2} \mathrm{Ph}$ & $\begin{array}{c}139.6,134.7,129.6 \\
127.7,50.4,45.6\end{array}$ & -55.4 & $-\cdots-$ & ----- \\
\hline
\end{tabular}


Polymerizations. Monomers were polymerized at $1 \mathrm{M}$ concentration with 1.5 6.0 equivalents of water in the appropriate alcohol (methanol for trimethoxysilanes, ethanol for triethoxysilanes). Aqueous $\mathrm{HCl}(1 \mathrm{~N})$ and $\mathrm{NaOH}(1 \mathrm{~N})$ were used as catalysts (2.7 mol $/ \mathrm{mol} \%$ catalyst relative to monomer concentration). All experiments were performed in triplicate. Polymerizations with three equivalents (relative to monomer) anhydrous formic acid or with catalytic aqueous tetrabutylammonium fluoride were also examined with select monomers. If gels were obtained at $1 \mathrm{M}$ monomer concentration, the monomer was then polymerized at lower concentrations to determine the practical gelation threshold. If the monomer did not gel within a maximum of two weeks, it was then polymerized at as high a concentration as possible (based on the molecular weight and density of the monomer). Soluble polysilsesquioxanes were described as resins. Gels were described as either colloidal (opaque white) or translucent (blue tinted) or transparent. Gels were prepared for further characterization by crushing and washing in water and diethyl ether, then drying under vacuum at $100^{\circ} \mathrm{C}$ overnight.

The resulting xerogels were characterized by solid state ${ }^{13} \mathrm{C}$ and ${ }^{29} \mathrm{Si} \mathrm{CP}$ MAS NMR and the chemical shifts are reported in Table $\mathbf{2}$ and are typical for hydrido-, alkyl-, and vinyl polysilsesquioxanes. Solid state ${ }^{13} \mathrm{C}$ and ${ }^{29} \mathrm{Si}$ CP MAS NMR spectra were obtained with a Bruker AMX-400 MHz spectrometer at $100.63 \mathrm{MHz}$ and $79.5 \mathrm{MHz}$, respectively, and were acquired with magic angle spinning (MAS) speeds of $\sim 5 \mathrm{kHz}$ and $-3-5 \mathrm{kHz}$, respectively. ${ }^{13} \mathrm{C}$ NMR spectra were acquired using cross polarization $(\mathrm{CP})$ with a relaxation delay of $1 \mathrm{sec}$ and a cross polarization time of $2 \mathrm{msec} .{ }^{13} \mathrm{C}$ referencing was performed on the carbonyl resonance of solid glycine $(\delta=176.0)$. Since the gels in 
this study are similar, these parameters were optimized on only one of the gels to obtain spectra with a satisfactory signal to noise ratio. ${ }^{29} \mathrm{Si} \mathrm{NMR} \mathrm{spectra} \mathrm{were} \mathrm{acquired} \mathrm{using}$ single pulse excitation with a relaxation delay of $480 \mathrm{sec}$. With ${ }^{29} \mathrm{Si} \mathrm{T}_{1}$ values ranging from 19 to $135 \mathrm{sec}$, the relaxation delay of $\geq 3 \mathrm{~T}_{1}$ is sufficient for quantitative spectra. ${ }^{29} \mathrm{Si}$ CP MAS NMR spectra were deconvoluted using a Lorentz-Gaussian (50:50) fit. As with other silsesquioxane materials, the spectra have peaks progressively upfield from the monomer with higher degrees of condensation.

Porosity was evaluated by nitrogen sorption porosimetry and scanning electron microscopy. Porosimetry measurements were determined using a Quantachrome Autosorb- 6 multiport nitrogen porosimeter. Surface areas were determined using the multi-point BET (Brunauer-Emmett-Teller) method. The $\mathrm{P} / \mathrm{P}_{\mathrm{o}}$ range was $0.05 \leq \mathrm{P} / \mathrm{P}_{\mathrm{o}} \leq$ 0.35. The average pore diameter was calculated from $d_{a v}$. 
Table 2. Solid state CP MAS ${ }^{29} \mathrm{Si}$ and ${ }^{13} \mathrm{C}$ NMR chemical shifts for peaks observed in gels. Monomer ${ }^{29} \mathrm{Si}$ (solution) chemical shifts are given for the $\mathrm{T}^{0}$ values in parentheses. ${ }^{14}$

\begin{tabular}{|c|c|c|c|c|c|}
\hline Monomer & $T^{0}$ & $T^{T}$ & $\mathbf{T}^{2}$ & $\mathrm{~T}^{3}$ & ${ }^{13} \mathrm{C}$ Resonances \\
\hline $\mathrm{HSi}(\mathrm{OMe})_{3}$ & $(-55.4)$ & Not Obs. & -74.6 & -84.7 & - \\
\hline $\mathrm{H} \mathrm{Si}(\mathrm{OEt})_{3}$ & $(-59.1)$ & Not Obs. & -74.6 & -84.9 & - \\
\hline $\mathrm{MeSi}(\mathrm{OMe})_{3}$ & $\begin{array}{c}-39.8 \\
(-40.1)\end{array}$ & Not Obs. & -57.0 & -65.2 & -4.2 \\
\hline $\mathrm{MeSi}(\mathrm{OEt})_{3}$ & $(-44.1)$ & -50.9 & -58.8 & -65.3 & -4.1 \\
\hline $\mathrm{EtSi}(\mathrm{OEt})_{3}$ & $(-45.7)$ & Not Obs. & Not Obs. & -66.5 & -5.8 \\
\hline $\mathrm{VinylSi}(\mathrm{OMe})_{3}$ & $(-55.9)$ & Not Obs. & -71.4 & -80.3 & $136.0,130.3$ \\
\hline VinylSi(OEt) ${ }_{3}$ & $(-59.1)$ & Not Obs. & -71.5 & & $135.8,130.5$ \\
\hline $\begin{array}{l}\text { Hexadecyl } \\
\mathrm{Si}(\mathrm{OMe})_{3}\end{array}$ & $(-42.9)$ & -49.8 & -58.0 & -66.7 & $32.8,24.1,14.2$ \\
\hline $\begin{array}{l}\text { Hexadecyl } \\
\mathrm{Si}(\mathrm{OEt})_{3}\end{array}$ & $(-45.8)$ & -49.0 & -57.3 & -66.5 & $32.6,24.0,14.1$ \\
\hline $\begin{array}{l}\text { Octadecyl } \\
\mathrm{Si}(\mathrm{OMe})_{3}\end{array}$ & $\begin{array}{c}-42.2 \\
(-42.9)\end{array}$ & -49.3 & -58.0 & -67.1 & $32.7,24.3,14.2$ \\
\hline $\begin{array}{l}\text { Octadecyl } \\
\mathrm{Si}(\mathrm{OEt})_{3}\end{array}$ & $(-45.7)$ & -50.5 & -58.2 & -66.0 & $32.8,24.3,14.3$ \\
\hline $\begin{array}{l}\text { Chloromethyl- } \\
\mathrm{Si}(\mathrm{OMe})_{3}\end{array}$ & $(-54.8)$ & -59.2 & -68.7 & -78.4 & 24.7 \\
\hline $\begin{array}{l}\text { Chloromethyl- } \\
\mathrm{Si}(\mathrm{OEt})_{3}\end{array}$ & $(-58.7)$ & Not Obs. & -68.2 & -78.2 & 24.7 \\
\hline $\begin{array}{c}\text { Chloromethyl } \\
\text { PhenylSi(OMe) })_{3}\end{array}$ & $(-55.4)$ & Not Obs. & -70.7 & -77.5 & $\begin{array}{c}139.8,134.2 \\
127.9,45.9\end{array}$ \\
\hline
\end{tabular}


Microscopy studies were performed using a Hitachi S4500 field emission scanning electron microscope. The samples were coated with 100-200 A chromium using a Gatan Model 681 High Resolution Ion Beam coater. Secondary electron images were taken using $5 \mathrm{KV}$ accelerating voltage. The images were acquired digitally from the SEM using a PGT Imix imaging system. Precipitates were examined by microscopy to determine if they were crystalline or amorphous.

\section{Results and Discussion}

Hydrolysis and condensation of trialkoxysilanes readily affords oligomeric and polymeric silsesquioxanes in the form of phase separated oils, resins and precipitates; gels were only observed with 14 out of 41 (34\%) of the monomers in this study (Tables 3 and 4). Only a few of the monomers that did not gel remained as solutions. Phase separation of oligomers and polymers from the solution dominated the polymerization reactions. Crystalline polyhedral oligosilsesquioxanes were observed with many of the alkyl-substituted monomers, despite the high monomer concentrations used. For the most part, the non-gel products were not fully characterized. Many of the polysilsesquioxane gels that did form were opaque white and colloidal in appearance. 
Table 3. Range of products obtained from organotrimethoxysilanes. Sol refers to a homogeneous solution. Crystalline products were generally minor contributors to the polysilsesquioxane products; most of the product was either in solution or in an oil or resinous phase. Precipitates are insoluble, non-crystalline materials. Grey indicates that polysilsesquioxane was observed in the indicated physical form. White indicates the polysilsesquioxane failed to afford the indicated physical form.

\begin{tabular}{|c|c|c|c|c|c|c|}
\hline R Group & Gel & Sol & Crystal & Oil & Resin & Precip. \\
\hline \multicolumn{7}{|l|}{$\mathrm{H}$} \\
\hline \multicolumn{7}{|l|}{ Methyl } \\
\hline \multicolumn{7}{|l|}{ Ethyl } \\
\hline \multicolumn{7}{|l|}{ Propyl } \\
\hline \multicolumn{7}{|l|}{$n$-Butyl } \\
\hline \multicolumn{7}{|l|}{$i$-Butyl } \\
\hline \multicolumn{7}{|l|}{$t$-Butyl } \\
\hline \multicolumn{7}{|l|}{ Hexyl } \\
\hline \multicolumn{7}{|l|}{ Octyl } \\
\hline \multicolumn{7}{|l|}{ Decyl } \\
\hline \multicolumn{7}{|l|}{ Dodecyl } \\
\hline \multicolumn{7}{|l|}{ Hexadecyl } \\
\hline \multicolumn{7}{|l|}{ Octadecyl } \\
\hline \multicolumn{7}{|l|}{ Cyclohexyl } \\
\hline \multicolumn{7}{|l|}{ Vinyl } \\
\hline \multicolumn{7}{|l|}{ Phenyl } \\
\hline \multicolumn{7}{|l|}{ Phenethyl } \\
\hline \multicolumn{7}{|l|}{ Chloromethyl } \\
\hline \multicolumn{7}{|l|}{ (p-Chloromethyl)phenyl } \\
\hline $\begin{array}{l}\text { Tridecafluoro-1,1,2,2- } \\
\text { tetrahydrooctyl }\end{array}$ & & & & & & \\
\hline
\end{tabular}


Table 4. Range of products obtained from organotriethoxysilanes. Sol refers to a homogeneous solution. Crystalline products were generally minor contributors to the polysilsesquioxane products; most of the product was either in solution or in a oil or resinous phase. Precipitates are insoluble, non-crystalline materials. Grey indicates that polysilsesquioxane was observed in the indicated physical form. White indicates the polysilsesquioxane failed to afford the indicated physical form.

\begin{tabular}{|c|c|c|c|c|c|c|}
\hline R Group & Gel & Sol & Crystal & Oil & Resin & Precip. \\
\hline OEt & & & & & & \\
\hline H & & & & & & \\
\hline Methyl & & & & & & \\
\hline Ethyl & & & & & & \\
\hline Propyl & & & & & & \\
\hline$i$-Propyl & & & & & & \\
\hline n-Butyl & & & & & & \\
\hline$i$-Butyl & & & & & & \\
\hline$t$-Butyl & & & & & & \\
\hline Hexyl & & & & & & \\
\hline Octyl & & & & & & \\
\hline Decyl & & & & & & \\
\hline Dodecyl & & & & & & \\
\hline Hexadecyl & & & & & \\
\hline Octadecyl & & & & & & \\
\hline Cyclohexyl & & & & & & \\
\hline Vinyl & & & & & & \\
\hline Phenyl & & & & & & \\
\hline Benzyl & & & & & & \\
\hline Phenethyl & & & & & & \\
\hline Chloromethyl & & & & & & \\
\hline Tridecafluoro-1,1,2,2- & & & & & \\
\hline tetrahydrooctyl & & & & & \\
\hline
\end{tabular}


In addition to screening monomers for gelation, the time required for the gels was noted. This data are useful practically for designing sol-gel experiments with organotrialkoxysilanes. In order to allow the relative gel times to be compared, gel times for the various monomers were obtained with $1 \mathrm{M}$ monomer concentration when possible. Gel times under these conditions ranged from immediate gelation for octadecyltriethoxysilane under acidic conditions to months for chloromethyltriethoxysilane. Under the same conditions used to polymerize the organotrialkoxysilanes, tetramethoxysilane (TMOS) and tetraethoxysilane (TEOS) form transparent or translucent silica gels. Under acidic conditions, TMOS formed transparent gels in 60 days at $1 \mathrm{M}$ monomer concentration and in 7 days at $5.3 \mathrm{M}$ (neat) monomer concentration. Under basic conditions, TMOS formed transparent gels overnight at $1.0 \mathrm{M}$. TEOS was less reactive under acidic conditions, going 8 months without forming gels as $1 \mathrm{M}$ solutions and forming only precipitates at $3.75 \mathrm{M}$. Under neutral conditions, translucent gels formed after 148 days. Base-catalyzed polymerization of TEOS afforded white, colloidal silica gels overnight. In the group of polysilsesquioxanes that did form gels, gel times were generally much shorter than for the silica gels prepared under similar conditions (Table 5). 
Table 5. Gel times for organotrialkoxysilanes. Where possible, gel times are given for $1.0 \mathrm{M}$ monomer concentration. In all experiments, monomers were reacted with 1.5 equivalents water.

\begin{tabular}{|c|c|c|c|c|}
\hline \multirow{3}{*}{ R Group } & \multicolumn{4}{|c|}{ Alkoxide Group, $\mathrm{Si}\left(\mathrm{OR}^{\prime}\right)_{3}$} \\
\hline & \multicolumn{2}{|c|}{ Methoxide } & \multicolumn{2}{|c|}{ Ethoxide } \\
\hline & Conditions & $\begin{array}{c}\text { Gel } \\
\text { Time }\end{array}$ & Conditions & $\begin{array}{c}\text { Gel } \\
\text { Time }\end{array}$ \\
\hline OR' & $\begin{array}{c}\mathrm{H}^{+}, 1.0 \mathrm{M}^{\mathrm{a}} \\
\mathrm{OH}^{-}, 1.0 \mathrm{M} \\
\mathrm{H}_{2} \mathrm{O}, 1.0 \mathrm{M}^{\mathrm{b}}\end{array}$ & $\begin{array}{l}60 \mathrm{~d} \\
12 \mathrm{~h} \\
64 \mathrm{~d} \\
\end{array}$ & $\begin{array}{c}\mathrm{H}^{+}, 1.0 \mathrm{M} \\
\mathrm{H}_{2} \mathrm{O}, 1.0 \mathrm{M}^{\mathrm{b}} \\
---\end{array}$ & $\begin{array}{c}300 \mathrm{~d} \\
148 \mathrm{~d}- \\
--\end{array}$ \\
\hline $\mathrm{H}$ & $\begin{array}{c}\mathrm{H}^{+}, 1.0 \mathrm{M}^{\mathrm{c}} \\
\mathrm{H}_{2} \mathrm{O}, 1.0 \mathrm{M}^{\mathrm{c}}\end{array}$ & $\begin{array}{l}15 \mathrm{~h} \\
15 \mathrm{~h}\end{array}$ & $\begin{array}{c}\mathrm{H}^{+}, 1.0 \mathrm{M} \\
\mathrm{H}_{2} \mathrm{O}, 1.0 \mathrm{M}^{\mathrm{c}}\end{array}$ & $\begin{array}{l}2 \mathrm{~d} \\
2 \mathrm{~d}\end{array}$ \\
\hline Methyl & $\begin{array}{l}\mathrm{H}^{+\dagger}, 5.85 \mathrm{M} \\
\mathrm{OH}^{-}, 1.0 \mathrm{M}^{\mathrm{c}}\end{array}$ & $\begin{array}{l}12 \mathrm{~h} \\
12 \mathrm{~h}\end{array}$ & $\begin{array}{c}\mathrm{H}^{+}, 4.25 \mathrm{M} \\
\mathrm{OH}^{-}, 1.0 \mathrm{M}^{\mathrm{b}}\end{array}$ & $\begin{array}{c}9 \mathrm{~d} \\
12 \mathrm{~h}\end{array}$ \\
\hline Ethyl & --- & --- & $\mathrm{OH}^{-}, 2.0 \mathrm{M}^{\mathrm{b}}$ & $12 \mathrm{~h}$ \\
\hline Vinyl & $\begin{array}{c}\mathrm{H}^{+\dagger}, 5.5 \mathrm{M} \\
\mathrm{OH}^{\prime}, 1.0 \mathrm{M}^{\mathrm{b}} \\
\end{array}$ & $\begin{array}{l}12 \mathrm{~d} \\
4 \mathrm{~d} \\
\end{array}$ & $\begin{array}{l}\mathrm{H}^{+}, 4.15 \mathrm{M} \\
\mathrm{OH}^{-}, 1.0 \mathrm{M}^{\mathrm{b}} \\
\end{array}$ & $\begin{array}{l}8 \mathrm{~d} \\
7 \mathrm{~d} \\
\end{array}$ \\
\hline$n$-Hexadecyl & $\begin{array}{c}\mathrm{H}^{+}, 1.0 \mathrm{M}^{\mathrm{d}} \\
\mathrm{OH}, 1.0 \mathrm{M} \\
\mathrm{H}_{2} \mathrm{O}, 2.35 \mathrm{M} \\
\end{array}$ & $\begin{array}{l}12 \mathrm{~h} \\
12 \mathrm{~h} \\
12 \mathrm{~h} \\
\end{array}$ & $\begin{array}{c}\mathrm{H}^{+}, 1.0 \mathrm{M}^{\mathrm{b}} \\
\mathrm{OH}^{-}, 1.0 \mathrm{M} \\
-\end{array}$ & $\begin{array}{c}10 \min 5 \\
\min -- \\
-\end{array}$ \\
\hline$n$-Octadecyl & $\begin{array}{c}\mathrm{H}^{+}, 1.0 \mathrm{M} \\
\mathrm{OH}^{-}, 1.0 \mathrm{M}^{\mathrm{d}} \\
\mathrm{H}_{2} \mathrm{O}, 1.0 \mathrm{M}^{\mathrm{e}}\end{array}$ & $\begin{array}{l}<1 \mathrm{~min} \\
4 \mathrm{~min} \\
17 \mathrm{~d} \\
\end{array}$ & $\begin{array}{c}\mathrm{H}^{+}, 1.0 \mathrm{M}^{\mathrm{e}} \\
\mathrm{OH}^{-}, 1.0 \mathrm{M}^{\mathrm{e}} \\
\mathrm{H}_{2} \mathrm{O}, 1.0 \mathrm{M}^{\mathrm{e}}\end{array}$ & $\begin{array}{l}<<1 \text { min } \\
2 \mathrm{~d} \\
<<1 \text { min }\end{array}$ \\
\hline Chloromethyl & $\begin{array}{c}\mathrm{H}^{+}, 5.4 \mathrm{M} \\
\mathrm{OH}^{-}, 1.0 \mathrm{M}^{\mathrm{a}} \\
\mathrm{H}_{2} \mathrm{O}, 1.0 \mathrm{M} \\
\end{array}$ & $\begin{array}{l}77 \mathrm{~d} \\
26 \mathrm{~d} \\
87 \mathrm{~d} \\
\end{array}$ & $\begin{array}{c}\mathrm{H}^{+}, 1.0 \mathrm{M}^{\mathrm{f}} \\
\mathrm{OH}^{-}, 1.0 \mathrm{M}^{\mathrm{b}} \\
\mathrm{H}_{2} \mathrm{O}, 1.0 \mathrm{M}\end{array}$ & $\begin{array}{l}172 \mathrm{~d} \\
2 \mathrm{~h} \\
76 \mathrm{~d} \\
\end{array}$ \\
\hline $\begin{array}{c}p \text {-Chloromethyl } \\
\text { phenyl }\end{array}$ & $\begin{array}{c}\mathrm{H}^{+}, 3.9 \mathrm{M} \\
\mathrm{OH}^{-}, 1.0 \mathrm{M}^{\mathrm{b}} \\
\mathrm{H}_{2} \mathrm{O}, 3.9 \mathrm{M}\end{array}$ & $\begin{array}{l}36 \mathrm{~d} \\
<1 \mathrm{~min} \\
15 \mathrm{~d}\end{array}$ & $\begin{array}{l}\cdots \\
\cdots-- \\
--\end{array}$ & $\begin{array}{l}--- \\
-\cdots \\
---\end{array}$ \\
\hline
\end{tabular}

† $0.1 \mathrm{M} \mathrm{HCl}$ used. At neat concentrations (not shown), these monomers produced the following results: a) Very exothermic, solution sprayed out of vial. b) Nonhomogeneous gel composed of a mixture of precipitates and gel. c) Exothermic reaction upon addition of aqueous catalyst caused bubbles throughout gel. d) Phase separation of heavy oil or gum from solution. e) Formation of precipitate. f) Phase separation and formation of hard resin. 


\section{Effect of Alkoxide}

The main difference between the trimethoxysilyl and triethoxysilyl monomers (Tables 3 and 4 ) is that the methoxide substituted monomers reacted faster and, in some

cases $(\mathrm{R}=$ methyl, ethyl, vinyl), so exothermically that the reaction solutions would explosively boil upon mixing and prior to gelation at concentrations higher than $1 \mathrm{M}$. Under these conditions, gels were obtained that were foam-like in consistency with pores large enough to be visible to the naked eye. In addition, the sol-gels were, with the exceptions of triethoxysilane and trimethoxysilane (vide infra), more exothermic under acid-catalyzed hydrolysis and condensation conditions than under neutral or basecatalyzed conditions. This increased reactivity has been attributed to inductive stabilization by the organic groups of positively charged intermediates and transition states in the hydrolysis and condensation reactions..$^{15}$

Effect of Monomer: Water Stoichiometry

While most of the monomers were polymerized with 1.5 equivalents of water, it is known that the ratio of monomer to water can have pronounced effects on the sol-gel chemistry of tetraalkoxysilanes. ${ }^{16}$ For organotrialkoxysilanes, a ratio of 1.5 equivalents of water to one equivalent of monomer is the ideal stoichiometry necessary for complete hydrolysis and condensation. Greater quantities of water increase hydrolysis and, thus, change the monomer composition during the sol-gel polymerization. More water also would be expected to make the solution more polar and, perhaps, less suitable to non-polar polysilsesquioxanes. Additional sol-gel polymerizations were performed with the phenyl-, benzyl-, and phenethyl-substituted monomers with 3.0 and 6.0 equivalents water under both acidic and basic conditions. 
In none of the systems, did the additional water lead to the formation of gels. It did, however, appear to cause phase separation of oily oligomers and resins. In an attempt

to avoid phase separation, the vinyl-, phenyl, ethyl-, $n$-butyl, $n$-hexyl and decyltriethoxysilanes were reacted neat with three equivalents of anhydrous formic acid in a non-aqueous sol-gel procedure developed by Sharp and Michaelzak. ${ }^{17}$ In all of these cases, no gels were obtained.

Effect of Sterics

The steric effect on gelation was probed with the series of monomers with organic groups of varying sterics. The expectation is that increasing steric bulk at the organic substituent will have a negative effect on the sol-gel polymerization process. Monomers with smaller organic groups, $\mathrm{R}=\mathrm{H}$, methyl, ethyl, should more readily hydrolyze and condense to afford polymers than those with bulkier groups, $\mathrm{R}=i$ propyl, $i$-butyl, cyclohexyl, and $t$-butyl, which would be expected to react less quickly and be less prone to form highly crosslinked polymers capable of forming gels. Pohl and Osterwald ${ }^{15}$ revealed that the acid- and base-catalyzed hydrolysis rates and acid catalyzed condensation rates decreased as the chain length increased from methyl to propyl, suggesting that there was a significant steric effect based on the alkyl group. The inability of $t$-butyltrialkoxysilanes to afford gels (Tables $3 \& 4$ ) and the isolation of the monomeric $t$-buylsilanetriol indicate that steric inhibition of hydrolysis and condensation reactions by the $t$-butyl group can effectively prevent polymeric gels from forming. However, one should be cautious about extending the steric effect argument to rationalizing the formation of gels from less sterically hindered monomers. Phase separation of oligomers and polymers from the sol-gel solution, before gelation can 
occur, appears to be a more important contributor than sterics to the inability of most alkyltrialkoxysilanes to afford gels.

Table 6. Appearance of monolithic polysilsesquioxane gels. Entries with dashed line indicate no gels were obtained.

\begin{tabular}{|c|c|c|c|c|c|c|}
\hline \multirow[b]{2}{*}{$\mathbf{R}$} & \multicolumn{3}{|c|}{$\mathrm{RSi}(\mathrm{OMe})_{3}$} & \multicolumn{3}{|c|}{ RSi(OEt) $)_{3}$} \\
\hline & $\mathbf{H}^{+}$ & $\mathrm{OH}^{-}$ & $\mathrm{H}_{2} \mathrm{O}$ & $\mathbf{H}^{+}$ & $\mathrm{OH}^{-}$ & $\mathrm{H}_{2} \mathrm{O}$ \\
\hline $\mathrm{H}$ & transl. & transl. & transl. & transp. & transp. & --- \\
\hline $\mathrm{CH}_{3}$ & opaque & transl. & --- & transl. & opaque & --- \\
\hline $\mathrm{CH}_{3} \mathrm{CH}_{2}$ & --- & --- & -- & --- & opaque & --- \\
\hline Dodecyl & -- & --- & --- & opaque & opaque & -- \\
\hline Hexadecyl & opaque & opaque & opaque & opaque & opaque & -- \\
\hline Octadecyl & opaque & opaque & opaque & --- & -- & --- \\
\hline Vinyl & opaque & opaque & -- & transl. & opaque & -- \\
\hline $\mathrm{ClCH}_{2}$ & transl. & opaque & transp. & -- & opaque & transp. \\
\hline$\left(\mathrm{p}-\mathrm{ClCH}_{2}\right)$ phenyl & -- & opaque & opaque & --- & $\cdots$ & --- \\
\hline
\end{tabular}

The first monomers in this series are trimethoxysilane and triethoxysilane. Hydrogen functionalized silsesquioxane gels are of interest because of the reactive nature of the hydrogen group towards bases, radical reactions, and hydrosilation chemistry. While trimethoxysilane and triethoxysilane, $\mathrm{R}=\mathrm{H}$, bear the smallest "organic" substituent, the reactive character of the hydrogen group as a reducing agent makes comparison with the aliphatic substituents in the series difficult under basic conditions, where the hydride group reacts with hydroxide to give hydrogen gas and silica gels. ${ }^{9}$ In contrast, the monomers polymerized rapidly and exothermically under acidic conditions or even with deionized water $(\mathrm{pH} 7)$ to afford insoluble, monolithic gels with at least some of the hydrogen groups intact. Following the reactivity trend observed with the 
polymerization of tetralkoxysilanes, trimethoxysilane polymerized to from gels more readily and at lower concentrations $(0.1 \mathrm{M})$ than triethoxysilane. The trialkoxysilane monomers $(\mathrm{R}=\mathrm{H})$ were the only subgroup of monomers that gave transparent gels of optical quality comparible to silica gels prepared from tetraalkoxysilanes.

Retention of the hydrogen group in the final xerogels increases, with decreasing $\mathrm{pH}$, in the sol-gel polymerization. Examination of the xerogels by solid state ${ }^{29} \mathrm{Si}$ NMR (CP MAS) spectroscopy (Figure 1) reveals a polysilsesquioxane structure for the gels prepared under acidic conditions, but both silica and silsesquioxanes architectures were present from both methoxy- and ethoxy-substituted monomers that were polymerized with dionized water at $1 \mathrm{M}$ monomer concentrations. This is evidenced by only traces of silica were observed from the reaction of the neat monomer with dionized water. This indicates that under these conditions, the rates of polymerization for the monomers are competitive with loss of hydrogen with gelation effectively shutting down conversion to silica. The solid state spectra for the gels prepared under basic conditions reveal only silica (Q) resonances. Caution must be exercised in using these monomers, however, as reaction conditions with higher $\mathrm{pH}$ and/or longer gel times may lead to significant reduction in the population of hydrogen groups retained in the final materials. 

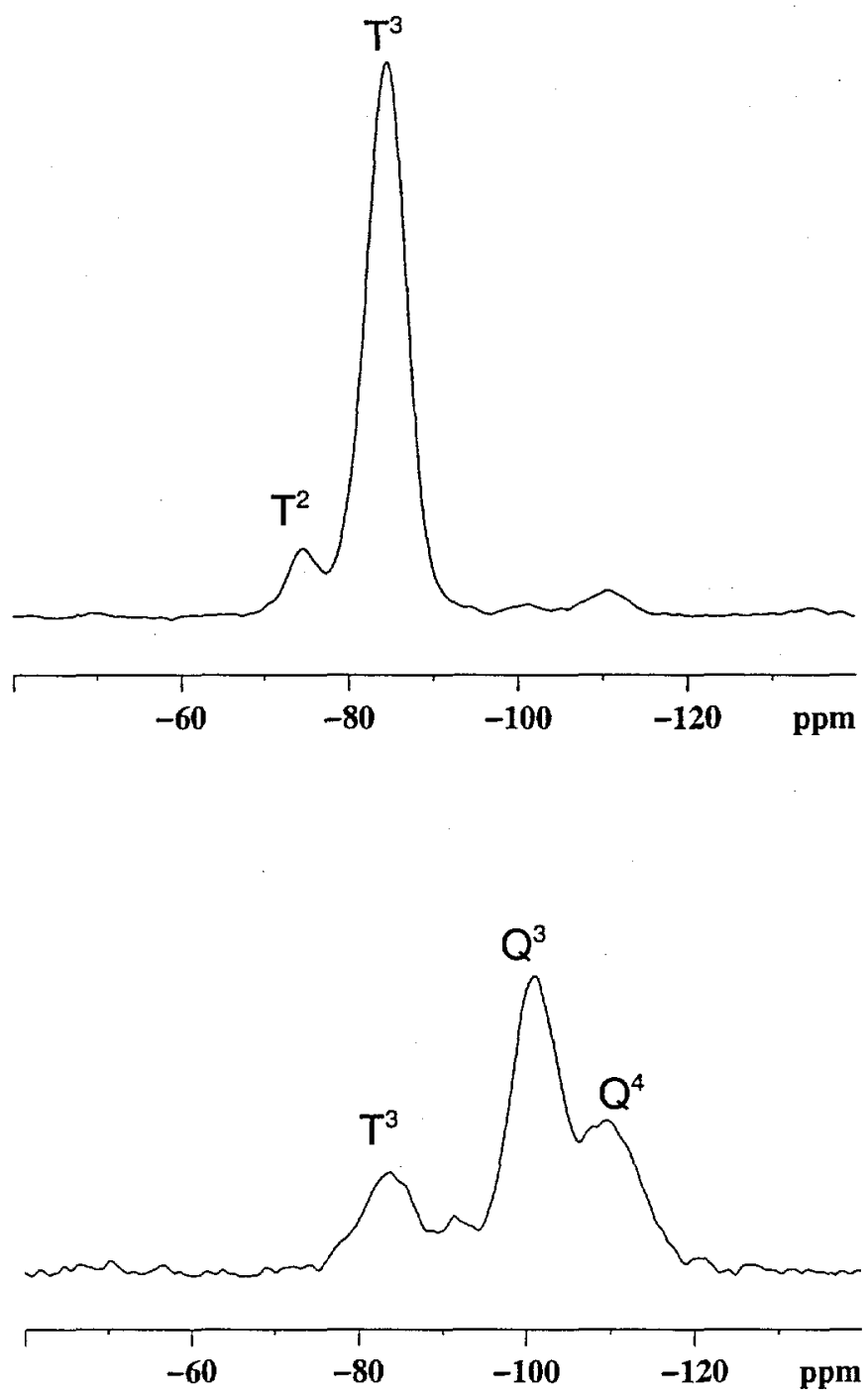

Figure 1. Solid state ${ }^{29} \mathrm{Si}$ CP MAS NMR of the polyhydrosilsesquioxane xerogel (top) prepared from the HCl-catalyzed sol-gel polymerization of triethoxysilane $(1 \mathrm{M}, \mathrm{EtOH}$, $1.5 \mathrm{H}_{2} \mathrm{O}$ ) and the polyhydrosilsesquioxane-silica gel (bottom) prepared with $\mathrm{NaOH}$ as catalyst.

Methylsilsesquioxane gels have been reported elsewhere ${ }^{5,6,12}$ and are, perhaps, the most studied of silsesquioxane systems capable of gelation. In this study, gels formed from both trimethoxy- and triethoxy-substituted monomers under basic and acidic 
conditions, but not at neutral pH. At $1.0 \mathrm{M}$, methyltrimethoxysilane reacted with acid to give mixtures of tacky resins and crystalline products that phase separated from the solution. At $5.85 \mathrm{M}$ (neat) monomer mixed with water and catalyst, the polymerization was exothermic enough to boil the solution (CAUTION); an opaque white gel was obtained. Under basic conditions, translucent gels formed overnight at $1.0 \mathrm{M}$ monomer concentration and in 5 days at $0.8 \mathrm{M}$ monomer concentration. Methyltriethoxysilane also reacted under acidic conditions to form mixtures of resin and crystalline products that phase separated from the solution at $1.0 \mathrm{M}$ monomer concentration and poorly defined gels with some occluded crystals or precipitates were obtained when $4.25 \mathrm{M}$ (neat) monomer was polymerized. Under basic conditions, yellow-tinted gels were obtained overnight. Only solutions free of crystals were formed under neutral conditions.

Changing the alkyl group from methyl to ethyl resulted in a remarkable reduction in the number of polymerization conditions that would lead to gels. Only the ethyltriethoxysilane monomer formed gels and then only after 8 days with $\mathrm{NaOH}$ as catalyst and at 2.0 M monomer concentration. These gels were colloidal in appearance and were insoluble in organic solvents or water. Under other basic conditions resins or precipitates were obtained. Under acidic conditions, resins and small amounts $(<5 \mathrm{wt} \%)$ of crystalline products were obtained. With deionized water, phase separated oils or resins were obtained. The ethyltrimethoxysilane afforded no gels under any conditions. No gels were obtained under any conditions with the $n$-propyl- or $n$-butyltrialkoxysilanes.

Increasing the steric hinderence at the silicon with branched alkyl groups ( $i$-butyl, $i$-propyl, cyclohexyl, $t$-butyl) prevented polymerizations of organotrialkoxysilanes from 
forming gels under any conditions. Even when neat monomers were mixed with aqueous acid or base in the absence of a solvent, only oligomeric and polymeric materials were obtained through some type of phase separation (separation of oil, resin, precipitation or crystallization) rather than gel-forming network polymers. These products were generally soluble in more non-polar organic solvents or at higher dilution in alcohols. In some cases $(\mathrm{R}=\mathrm{Me}, \mathrm{Et}, i$-propyl, $i$-butyl), discrete polyhedral oligosilsesquioxanes, ${ }^{18}$ such as the cubic octomer $\left(\mathrm{T}_{8}\right)$ from $i$-butyltriethoxysilane (Figure 2), were obtained in sufficient quantities to isolate and characterize. However, the yields of crystalline products are low $(<10 \%)$ compared to literature procedures for preparing these compounds since the high monomer concentrations favor a more random assortment of products that generally separate from the solvent as a viscous hydrophobic resin.

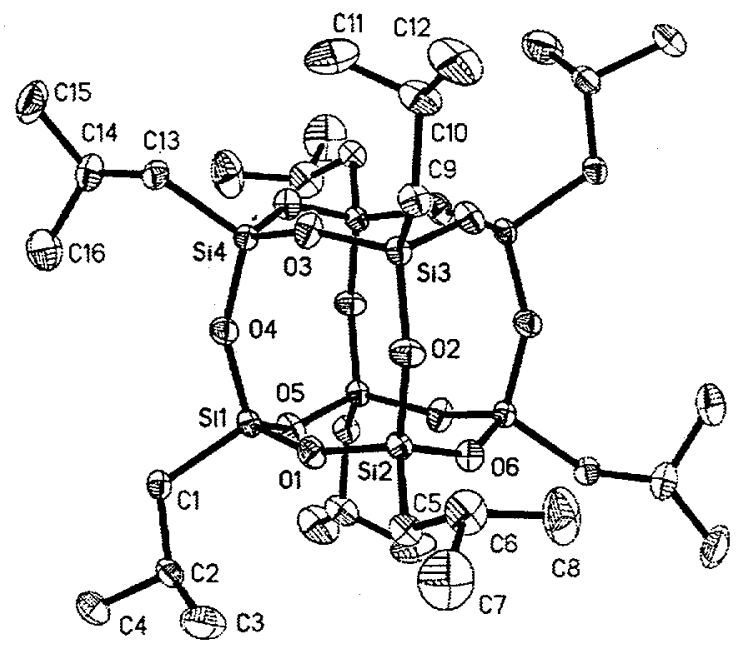

Figure 2. Ortep drawing for the crystal structure of $T_{8}$ cube obtained from the polymerization of $i$-butyltriethoxysilane. 
Solution ${ }^{29} \mathrm{Si}$ NMR studies have revealed that hydrolysis and condensation of alkoxysilanes are generally slowed by the steric effect. $t$-Butyltrialkoxysilanes are sterically hindered enough that while complete hydrolysis eventually occurs, condensation reactions are inhibited such that even oligomers form only slowly. Solution ${ }^{29} \mathrm{Si}$ NMR of the polymerization reaction of $t$-butyltriethoxysilane under acidic conditions reveals only hydrolysis products $\left(\mathrm{T}^{0}\right)$ after $18 \mathrm{~h}$ and only minor resonances from $\mathrm{T}^{1}$ ( 1 siloxane bond) and $\mathrm{T}^{2}$ ( 2 siloxane bonds) peaks under basic conditions. Even after three months, $\mathrm{T}^{1}$ peaks dominate the ${ }^{29} \mathrm{Si}$ NMR spectra for the acid-catalyzed system. Thus, the $t$-butyl monomers are suitable for forming some discrete oligomeric products or for surface functionalization of surfaces, but not for forming resins and gels.

\section{Effect of Substitutent Length}

With increasing length of alkyl substituents, the silsesquioxanes become less prone to form gels. The reluctance of the ethyl-substituted monomers and the inability of the $n$-propyl, $n$-butyl, $n$-hexyl, $n$-octyl, $n$-decyl , $n$-dodecyl and tridecafluoro-1,1,2,2tetrahydrooctyl monomers to form gels may be more of a physical phenomenon than one of chemical reactivity. In every case, phase separation of a dense oil, resin, or precipitate from a less dense alcoholic phase was observed. Even performing non-aqueous sol-gel polymerizations with anhydrous formic acid failed to prevent phase separation and resin formation. Surprisingly with very long alkyl groups (hexadecyl and octadecyl) gelation is again observed, possibly due to supramolecular organization of the long alkyl groups. ${ }^{11}$ Hexadecyl- and octadecyltrimethoxysilanes polymerized to form opaque white gels under acidic, basic and neutral conditions. Hexadecyl-, and octadecyltriethoxysilanes also formed opaque white gels under acidic and basic conditions. Gels formed by phase 
separation of a colloidal species, followed by gelation. In both cases, gels formed at concentrations as low as $0.2 \mathrm{M}$. Below that concentration, the colloids precipitated. We were unable to observe any of the lamellar structures reported by A. Shimojima, et. al, ${ }^{11}$ in the gels we prepared. Furthermore, the gels were discovered to melt between 46-61 ${ }^{\circ} \mathrm{C}$ for the hexadecylsilsesquiuoxanes and $55-75{ }^{\circ} \mathrm{C}$ for the octadecylsilsesquioxanes. These results suggest that phase separation is occurring to form colloidal species in a similar fashion to that observed with shorter alkyl substituted monomers, but that the long chain hexadecyl and octadecyl substituents provide sufficient non-bonding interactions between colloids to facilitate gelation. Interestingly, the dried materials dissolve in hot benzene to form transparent solutions that, when cooled to room temperature, form transparent gels.

\section{Effect of Aryl-and Vinyl-Substituents}

Aryl containing substituents (phenyl, benzyl, and phenethyl) also formed soluble resinous oligomers with molecular weights under $10 \mathrm{~K}$ (by gel permeation chromatography). Even with heating to $200{ }^{\circ} \mathrm{C}$, the molecular weights $\left(\mathrm{M}_{\mathrm{w}}\right)$ of the oligomers remained under $20 \mathrm{~K}$ and no gels were obtained. Unlike the alkyl-substituted oligomers and polymers, it was possible to prepare aryl-substituted polysilsesquioxanes with glass transition temperatures above room temperature. The low molecular weight phenyl, benzyl, and phenethyl-substituted polysilsesquioxanes prepared by normal sol-gel techniques and dried without heating exhibited glass transition temperatures below -25 ${ }^{\circ} \mathrm{C} .19$ Heat treating the polymers at $100{ }^{\circ} \mathrm{C}$ or $200{ }^{\circ} \mathrm{C}$ significantly increased the $\mathrm{T}_{\mathrm{g}}$ 's to near room temperature or above. ${ }^{20}$ The phenyl-substituted monomer produced materials with the highest $T_{g}$ 's, ranging from $45-76{ }^{\circ} \mathrm{C}$. The polybenzylsilsesquioxanes (a single 
methylene spacer between the phenyl ring and the silicon) exhibited $T_{g}$ 's between 4-40 ${ }^{\circ} \mathrm{C}$ and the polyphenethylsilsesquioxanes (an ethylene spacer between the phenyl and the silicon) had the lowest $\mathrm{T}_{\mathrm{g}}$, at $-10{ }^{\circ} \mathrm{C}$ or below. Polysilsesquioxanes prepared with base catalysts exhibited $\mathrm{T}_{\mathrm{g}}$ 's of about $20^{\circ} \mathrm{C}$ higher than those prepared with acid catalysts.

In contrast with the aryl-substituted monomers, the vinyl-substituted monomers reacted to afford monolithic polysilsesquioxane gels. Colloidal white gels were obtained from the $\mathrm{NaOH}$ catalyzed polymerization of trimethoxyvinylsilane at concentrations ranging from neat monomer (immediate gelation) to as low as $0.6 \mathrm{M}$ (after 1 week). Under acidic conditions, spongy opaque gels were obtained at neat monomer concentration. Resins and crystals were obtained at lower monomer concentrations. All of the $\mathrm{HCl}$-catalyzed polymerizations of the trialkoxyvinylsilanes were exothermic. In many cases, the solution would boil upon mixing. Furthermore, triethoxyvinylsilane would only form translucent gels at the highest $(4.25 \mathrm{M})$ monomer concentration used when the reaction was $\mathrm{HCl}$-catalyzed. No gels were obtained under neutral conditions. Under basic conditions, opaque white gels were obtained with monomer concentrations as low as $0.8 \mathrm{M}$. The smaller steric bulk of the vinyl group compared to the phenyl may have contributed to gelation by allowing polymerization to higher molecular weights.

\section{Effect of Organofunctional Substituents}

Most organofunctional trialkoxysilanes reacted to form oils and polymeric products. Notable exceptions that readily formed gels were the chloromethyltrialkoxysilanes ${ }^{10}$ and chloromethylphenyltrimethoxysilane. These chloromethyl groups might be expected to undergo nucleophilic substitution reactions with hydroxide ions present under basic conditions. However, under the sol-gel 
conditions used in these experiments, the chloride substitutents in the chloromethyltrialkoxysilanes and chloromethylphenyltrimethoxysilane did not react, even when basic catalysts were used. Both solid state ${ }^{29} \mathrm{Si} \mathrm{NMR}$ and chlorine elemental analysis showed that little, if any, of the chlorine was lost during the sol-gel process.

\section{Polysilsesquioxane Xerogels}

Structural characterization of the xerogels using solid state ${ }^{29} \mathrm{Si}$ NMR revealed two different families of materials. The first was polysilsesquioxanes whose spectra revealed mostly fully condensed $\mathrm{T}^{3}$ and lesser contributions from $\mathrm{T}^{2}$ resonances (Figure 1). These spectra are consistent with what has been observed by others for polysilsesquioxanes. The second group was the thermoreversible hexadecyl- and octadecylsilsesquioxane gels that were not insoluble network polymers, but oligomers. As one would expect, the ${ }^{29} \mathrm{Si}$ NMR spectra of these materials exhibited greater contributions from $\mathrm{T}^{2}$ resonances, as well as $\mathrm{T}^{1}$ resonances (Figure 3).

Xerogels with $\mathrm{R}=\mathrm{H}$ or $\mathrm{Me}$ exhibited the highest surface areas $\left(>500 \mathrm{~m}^{2} / \mathrm{g}\right)$ and pores in the lower mesopore range $(<100 \AA)$. Most of the polysilsesquioxanes with organic groups had lower surface areas and larger pores than the polysilsesquioxanes with $\mathrm{R}=\mathrm{H}$, or were completely non-porous. Xerogels prepared under acidic conditions were often non-porous, whereas those prepared under basic conditions were generally porous. Exceptions to this were the chloromethylphenyl substituted polysilsesquioxane xerogels that were non-porous regardless of the experimental conditions used in their preparation. Xerogels prepared from sol-gel polymerizations, run at higher monomer concentration, generally possessed lower surface areas or were non-porous. 

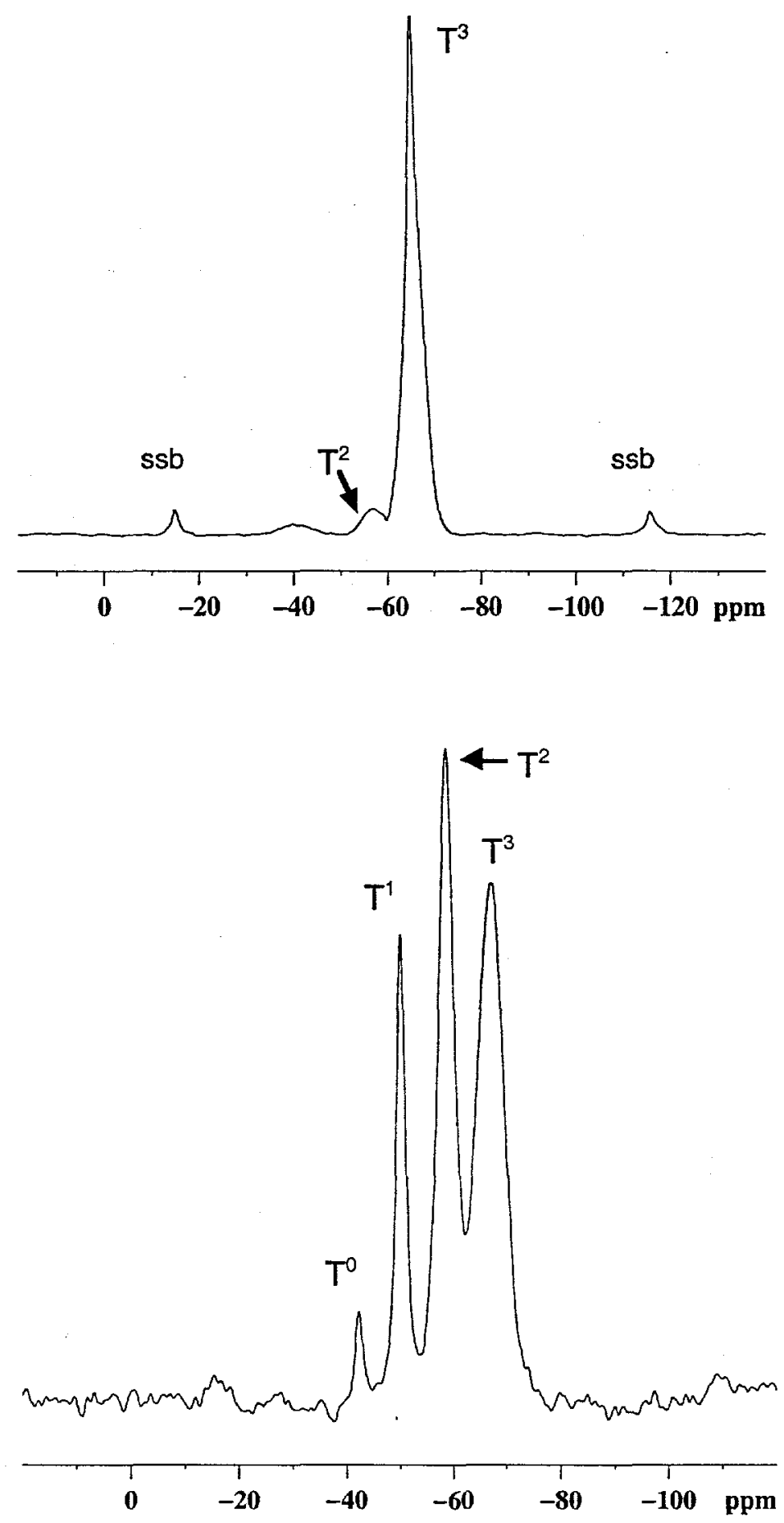

Figure 3. Solid state ${ }^{29} \mathrm{Si}$ CP MAS NMR of the polymethylsilsesquioxane xerogel (top) prepared from the $\mathrm{NaOH}$-catalyzed sol-gel polymerization of methyltrimethoxysilane (1 $\mathrm{M}$, EtOH, $1.5 \mathrm{H}_{2} \mathrm{O}$ ) showing that the material is highly condensed with its large $\mathrm{T}^{3}$ peak. In contrast, the polyoctadecylsilsesquioxane gel (bottom) prepared with $\mathrm{NaOH}$ as catalyst has much greater contributions of lesser condensed silsesquioxane silicons as evidenced by the greater contributions of the $\mathrm{T}^{1}$ and $\mathrm{T}^{2}$ resonances. 
Table 7. Surface areas and mean pore diameters for different $\mathrm{R}$ groups in $\mathrm{RSi}(\mathrm{OMe})_{3}$ based polysilsesquioxane xerogels. (a) Gels were obtained at $1.0 \mathrm{M}$ monomer concentration. (b) Monomer reacts violently, boiling the solution. (c) Gels were obtained at neat monomer concentration.

\begin{tabular}{|c|c|c|c|c|c|c|}
\hline \multirow[b]{2}{*}{ Catalyst } & \multicolumn{6}{|c|}{ Surface Area $\left(\mathrm{m}^{2} / \mathrm{g}\right) /($ Pore Diameter $(\AA))$} \\
\hline & OMe & $\mathbf{H}$ & Me & Vinyl & $\mathrm{ClCH}_{2}$ & $\mathrm{ClCH}_{2} \mathrm{Ph}$ \\
\hline $\mathrm{H}+$ & $246(22)^{\mathrm{a}}$ & $617(67)^{a}$ & $\begin{array}{c}\text { Non- } \\
\text { porous }^{c}\end{array}$ & $\begin{array}{c}\text { Non- } \\
\text { porous }^{c}\end{array}$ & $\begin{array}{c}\text { Non- } \\
\text { porous }^{\mathfrak{c}}\end{array}$ & $\begin{array}{c}\text { Non- } \\
\text { porous }^{c}\end{array}$ \\
\hline $\mathrm{H}_{2} \mathrm{O}$ & $342(50)^{a}$ & $393(45)^{\mathrm{a}}$ & No Gels & No Gels & $28(380)^{\mathrm{a}}$ & $\begin{array}{c}\text { Non- } \\
\text { porous }\end{array}$ \\
\hline $\mathrm{OH}-$ & $212(65)^{\mathrm{a}}$ & Reacts $^{\mathrm{b}}$ & $566(45)^{\mathrm{a}}$ & $70(407)^{\mathrm{a}}$ & $20(750)^{\mathrm{a}}$ & $\begin{array}{c}\text { Non- } \\
\text { porous }^{\mathrm{a}}\end{array}$ \\
\hline
\end{tabular}

Table 8. Surface areas and mean pore diameters for different $\mathrm{R}$ groups in $\mathrm{RSi}(\mathrm{OEt})_{3}$ based polysilsesquioxane xerogels. (a) Gels were obtained at $1.0 \mathrm{M}$ monomer concentration. (b) Monomer reacts violently, boiling the solution. (c) Gels were obtained at neat monomer concentration.

\begin{tabular}{|c|c|c|c|c|c|}
\hline \multirow{2}{*}{ Catalyst } & \multicolumn{5}{|c|}{ Surface Area $\left(\mathrm{m}^{2} / \mathbf{g}\right) /$ Pore Diameter $(\AA)$} \\
\cline { 2 - 6 } & OEt & $\mathbf{H}$ & Me & Vinyl & ClCH $_{2}$ \\
\hline $\mathrm{H}+$ & No Gels & $766(40)^{\mathrm{a}}$ & $226(56)^{\mathrm{c}}$ & $\begin{array}{c}\text { Non- } \\
\text { porous }\end{array}$ & $\begin{array}{c}\text { Non- } \\
\text { porous }^{\mathrm{c}}\end{array}$ \\
\hline $\mathrm{H}_{2} \mathrm{O}$ & $637(84)^{\mathrm{a}}$ & $662(41)^{\mathrm{a}}$ & No Gels & No Gels & $51(240)^{\mathrm{a}}$ \\
\hline $\mathrm{OH}-$ & No Gels & Reacts $^{\mathrm{b}}$ & $281(214)^{\mathrm{a}}$ & $140(338)^{\mathrm{a}}$ & $63(478)^{\mathrm{a}}$ \\
\hline
\end{tabular}

\section{Conclusions}

Polysilsesquioxane gels were prepared by the sol-gel polymerization of organotrialkoxysilanes, $\mathrm{RSi}\left(\mathrm{OR}^{\prime}\right)_{3}$, with $\mathrm{R}^{\prime}=\mathrm{Me}: \mathrm{R}=\mathrm{H}$, Me, vinyl, chloromethyl, chloromethylphenyl, hexadecyl, and octadecyl and $\mathrm{R}^{\prime}=\mathrm{Et}: \mathrm{R}=\mathrm{H}, \mathrm{Me}$, Et, chloromethyl, vinyl, dodecyl, and hexadecyl. The other substituents studied led to the formation 
oligomers and polymers in the form of oils and resins. Formation of gels from trialkoxysilanes is significantly hindered by phase separation of oligomeric or polymeric silsesquioxanes and, to a lesser extent, by sterically bulky organic substituents. Crystalline products were obtained, despite the high monomer concentrations used, from a few alkyl-substituted trimethoxysilanes and a variety of triethoxysilyl monomers under acidic conditions. The majority of the gels were opaque and colloidal in appearance. The gels with $\mathrm{R}=\mathrm{H}, \mathrm{Me}$, and chloromethyl were the most transparent. Most of the gelations were irreversible, but hexadecyl- and octadecylsilsesquioxane gels were thermoreversible between $45-75^{\circ} \mathrm{C}$.

The porosity of the xerogels was characterized by nitrogen porosimetry and scanning electron microscopy. Xerogels prepared from trimethoxysilane and triethoxysilane had the highest surface areas. Many of the remaining organotrialkoxysilanes formed porous polymeric gels, but the surface areas were lower and the mean pore sizes were larger. Some of the xerogels, especially those prepared under acidic conditions, were non-porous. Future efforts will be focused on the formation of gels from polar organotrialkoxysilanes that are more typically used for coupling agents.

\section{Acknowledgments}

We would like to thank Bonnie McKenzie for the scanning electron micrographs, Drs. Roger Assink and Todd Alam for solid state NMR spectroscopy, and Drs. David R. Wheeler and Gregory M. Jamison for numerous discussions. We would also like to thank Dr. Joseph Ziller at the University of California Irvine for the x-ray structure 
determination. Sandia is a multiprogram laboratory operated by Sandia Corporation, a Lockheed Martin Company, for the United States Department of Energy under Contract DE-AC04-94AL85000.

(1) Baney, R. H.; Itoh, M.; Sakakibara, A.; Suzuki, T. In Chem. Rev. (Washington, D. C.) 1995; Vol. 95, p 1409-30.

(2) Sanchez, C.; Ribot, F.; Lebeau, B. In J. Mater. Chem. 1999; Vol. 9, p 3544.

(3) Voronkov, M. G.; Lavrent'yev, V. I. In Top. Curr. Chem. 1982; Vol. 102, p 199-236.

(4) Slinyakova, I. B.; Samodumova, I. M.; Voronkov, M. G. In Kolloid. Zh. 1972; Vol. 34, p 574-8.

(5) Reetz, M. T.; Zonta, A.; Simpelkamp, J.; Rufinska, A.; Tesche, B. In J. Sol-Gel Sci. Technol. 1996; Vol. 7, p 35-43.

(6) Takamura, N.; Taguchi, K.; Gunji, T.; Abe, Y. In J. Sol-Gel Sci. Technol. 1999; Vol. 16, p 227-234.

(7) Budkevich, G. B.; Slinyakova, I. B.; Neimark, I. E. In U.S.S.R.; (Pisarzhevskii, L. V., Institute of Physical Chemistry).: SU, 1968.

(8) Belot, V.; Corriu, R.; Leclercq, D.; Mutin, P. H.; Vioux, A. In Chem. Mater. 1991; Vol. 3, p 127-31.

(9) Tour, J. M.; Kafka, C. M. In Adv. Mater. (Weinheim, Fed. Repub. Ger.) 1993; Vol. 5, p 47-9. 
(10) Slinyakova, I. B.; Voronkov, M. G.; Krot, I. E. In Kolloid. Zh. 1973; Vol. $35, \mathrm{p} 480-5$.

(11) Shimojima, A.; Sugahara, Y.; Kuroda, K. In Bull. Chem. Soc. Jpn. 1997; Vol. 70, p 2847-2853.

(12) Slinyakova, I. B.; Kurennaya, L. I. In Vysokomol. Soedin., Ser. B 1972; Vol. 14, p 889-92.

(13) Liepins, E.; Zicmane, I.; Lukevics, E. In Kremniiorg. Soedin. Mater. Ikh Osn., Tr. Soveshch. Khim. Prakt. Primen. Kremniiorg. Soedin., 5th 1984, p 16-19.

(14) Modified GE Silicon NMR nomenclature.

(15) Osterholtz, F. D.; Pohl, E. R. In J. Adhes. Sci. Technol. 1992; Vol. 6, p $127-49$.

(16) Brinker, C. J.; Scherer, G. W. Sol-Gel Science, The Physics and Chemistry of Sol-Gel Processing; Academic Press, Inc.: Boston, 1990.

(17) Sharp, K. G. In J. Sol-Gel Sci. Technol. 1994; Vol. 2, p 35-41.

(18) Voronkov, M. G.; Vlasova, N. N.; Pestunovich, A. E. In Russ. J. Gen. Chem. 1998; Vol. 68, p 770-774.

(19) Rahimian, K.; Loy, D. A.; Wheeler, D. R. In Polym. Prepr. (Am. Chem. Soc., Div. Polym. Chem.) 1998; Vol. 39, p 593-594.

(20) Schneider, D. A.; Loy, D. A.; Baugher, B. M.; Wheeler, D. R.; Assink, R. A.; Alam, T. M.; Saunders, R. In Polym. Prepr. (Am. Chem. Soc., Div. Polym. Chem.) 1998; Vol. 39, p 513-514. 